\title{
Optimization of Multi-Band Characteristics in Fan-Stub Shaped Patch Antenna for LTE (CBRS) and WLAN Bands
}

\author{
Khalid Ali Khan ${ }^{1, *}$, Suleyman Malikmyradovich Nokerov ${ }^{2}$ \\ ${ }^{1}$ Department of Electrical and Computer Engineering, Mettu University, Mettu, Ethiopia \\ ${ }^{2}$ Oguz Han Engineering and Technology University of Turkmenistan, Ashgabat, Turkmenistan \\ Received 07 November 2020; received in revised form 31 March 2021; accepted 01 April 2021 \\ DOI: https://doi.org/10.46604/peti.2021.6713
}

\begin{abstract}
This study aims to optimize a fan-stub slot patch to get better suitability and performance for Citizens Broadband Radio Service (CBRS). The transition from the tedious configuration of slotted patch antenna in fan-stub shape is evaluated. Also, the impact of stub width $W$, stub length $L$, and its orientation are tested. Multiple simulation tests ensure the uniqueness in the type of slots or stubs that affect the multiband nature of patch. The optimization of basic fan-stub structure on return loss $S_{11}$, Voltage Standing Wave Ratio (VSWR), and the operating band at the desired frequency is performed to accommodate the federal and non-federal use of the band. The simulation results show that the designed antenna is technically suitable to cover 4G LTE in CBRS (LTE-43 and LTE-48 band) as well as $5.5 \mathrm{GHz}$ Wireless Local Area Network (WLAN) band of operation.
\end{abstract}

Keywords: return loss $\mathrm{S}_{11}$, VSWR, CBRS band, LTE-43/LTE-48 band, WLAN, fan-stub, dielectric constant

\section{Introduction}

The recent rapid advancement in telecommunication systems is offering a variety of services, e.g., Internet access via the wireless network. Wireless networks use a specific range of spectrum for facilitating the services. Cellular networks such as Long Term Evolution (LTE), Wireless Local Area Network (WLAN), or multilayer spectrum-based systems including $5^{\text {th }}$ generation cellular systems are few of them. Reconfigurable Smart Surface (RSS) technology is considered to be a new cellular communication paradigm to improve services [1-2] in the communication world. Fractal Ultra-wideband (UWB) or multiband magneto-electric dipole antenna [3-4], Vivaldi antenna [5], lumped LC resonator antenna [6] all are portable and extendable antennas for wide applications. However, their fabrications are complex because of the multi-slots based geometry. LTE supports both duplexing technologies named as Frequency Division Duplex (FDD) technology and Time Division Duplex (TDD) technology, and works on a number of frequency bands. International Telecommunication Union (ITU) regularly expands the LTE frequency bands rapidly due to technical pressure caused by the growing need for mobile communication.

Recently, the frequency range of $450 \mathrm{MHz}$ to $3.8 \mathrm{GHz}$ is allocated for LTE system and Citizens Broadband Radio Service (CBRS) as well. Low power cellular systems such as CBRS that cover the band pair of LTE-42 band (3550 MHz to $3660 \mathrm{MHz}$ ) and LTE-43 band (3660 MHz to $3700 \mathrm{MHz}$ ) are expanded globally and also known as a licensed band in Japan and in other countries. CBRS also includes LTE-48 band (3550 MHz to $3700 \mathrm{MHz}$ ). LTE-48 band is the combination of LTE-42 band and LTE-43 band. Hence, it includes the frequency spectrum of both bands. Now in the USA, the LTE-48 band is also known as 4G LTE in CBRS band. In [7], CBRS spectrum sharing between unlicensed LTE (LTE-U) and Wi-Fi is reported with technical

* Corresponding author. E-mail address: sts.khalid@ gmail.com

Tel.: +251-954591921 
challenges. Three classes of users with hierarchical priority in CBRS band have been also presented. CBRS spectrum in which Incumbent Access (IA) users, Prioritized Access License (PAL) users, and General Authorized Access (GAA) users come under the Tier-1, Tier-2 and Tier-3 respectively are shown in Fig. 1. Depending upon the spectrum of CBRS band, all concerned users (from Tier-1 to Tier-3) can be also prioritized with decreasing interference protection fashion as demonstrated in Fig. 2. In the current scenario, the expansion of unlicensed LTE (LTE-U) as PAL or GAA users in the CBRS band is an enticing choice because of the high penetration at $3.5 \mathrm{GHz}$, clean channel, and wide amount of spectrum [8].

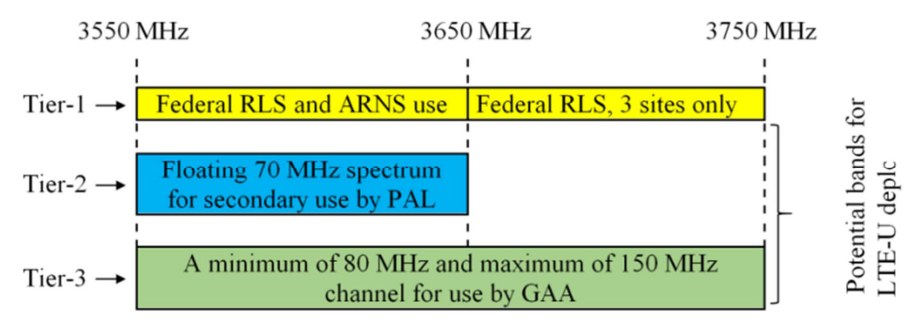

Fig. 1 CBRS spectrum for three types of users [7]

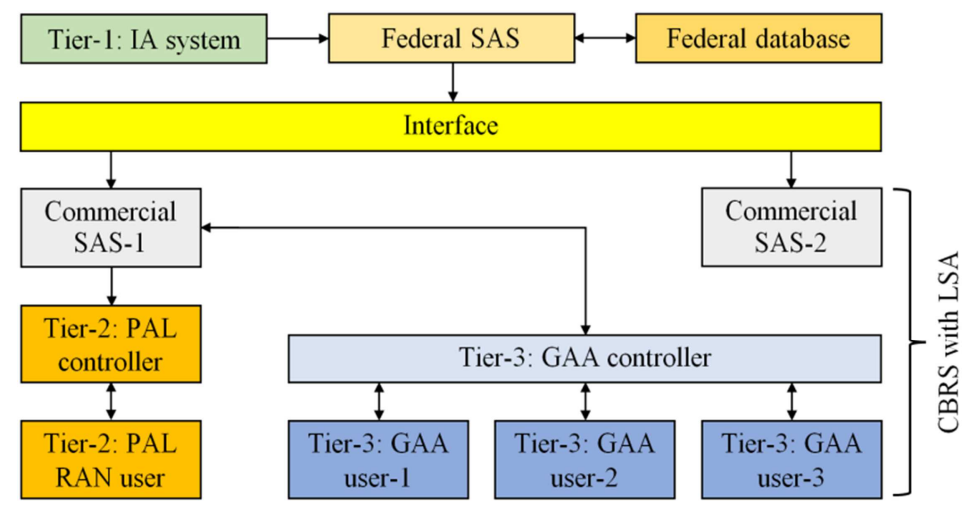

Fig. 2 Users access priority [7]

The design and optimization of new compact antennas for better radiation characteristics with multi-band features are the new challenge for antenna designers and researchers. Several studies in this context have been the matter of interest and are still going on. However, some specific band antennas or UWB, which brings fabrication complexity and unsuitability for limited space [9], all are relatively large in size [10] or complex in geometry. Vivaldi antennas are the major development in the history for UWB antennas [11-16]. Moosazadeh et al. [17] designed an Antipodal Vivaldi antenna with additional slots, but it is not fitted for LTE spectrum range.

Almost all Vivaldi antennas are operational above $5 \mathrm{GHz}$ as referred below. Much designing literature related to the planer UWB antenna with the band notched characteristics is also available. However, those designs are based on different type of stubs, slots, arms, and slits in the radiating element to control the radiation performance. Additionally, at the same time, interference may exist between them if they are not adjusted properly [18]. Novel structured UWB antennas with $\mathrm{S}_{11}$ less than $-20 \mathrm{~dB}$ have been also proposed to cover the 5.2/5.8 GHz WLAN system [19-20], but their multistage recumbent structure and configuration brings complexity in its fabrication steps. Historically, materials with the low dielectric constant $\left(\varepsilon_{r}\right)$ such as different classes of Rogers material have been in extensive use as an antenna's substrate [21-22] for all kinds of telecommunication antennas except biomedical applications based antennas [23-28].

The proposed antenna is planer in nature and exhibits advantages in terms of easy fabrication because of its simple geometry. It also offers compactness in size and multiband characteristics with very low Voltage Standing Wave Ratio (VSWR < 1.3) at its central resonance frequency in each band. Here, the optimization by Monte Carlo method is used to decide the specific limit of antenna structure and its variable parameter. Consequently, it shows the satisfactory performance and reasonable operation in 4G (LTE in CBRS) band including 5.5 GHz WLAN systems. 
Monte Carlo method is a simulation technique based on random sampling in order to get the numerical solution of mathematical problems [29] although it is very difficult to find a method that would bring the complete solution by optimization. Furthermore, the optimal dimension of the investigated antenna and other parameters are derived from simulation results individually, irrespective of other variables. For example, in the case of fan-stub, while optimizing the angle and remaining the geometrical parameters, the width $W$ and length $L$ are treated as a constant. This process will be repeated and completed for all parameters step by step. Obviously, the multiband nature with state of frequencies can be changed by changing the antenna configuration [30-32].

\section{Fan-Stub Antenna and Its Optimization to Matching}

The general geometry of fan-stub planer patch antenna is shown in Fig. 3(a). It consists of the length $L$, width $W$, and angle $\theta$ that can be treated as its dimensional parameters. When the angle of the structure is adjusted between $0^{\circ}$ to $180^{\circ}\left(0^{\circ}<\theta<\right.$ $180^{\circ}$ ) with any value of the length $L$ and width $W$, it appears as fan-stub. However, in suggested geometry, this angle is typically chosen between $\pi$ and $2 \pi\left(180^{\circ}<\theta<360^{\circ}\right)$ and looks like a sectored circular patch as depicted in Fig. 3(b). Rogers (RO3035) with dielectric constant $\varepsilon_{r}$ of 3.6 is used as a substrate and has the height of $5.0 \mathrm{~mm}$. The copper metal that has the thickness and conductivity as $0.035 \mathrm{~mm}$ and $5.8 \cdot 10^{7} \mathrm{~s} / \mathrm{m}$ respectively is placed over substrate as a radiating element.

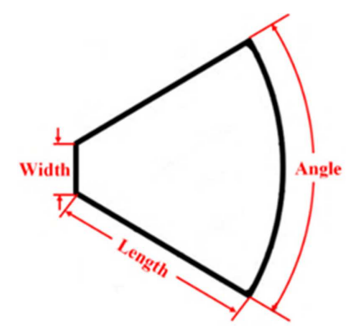

(a) General fan-stub geometry

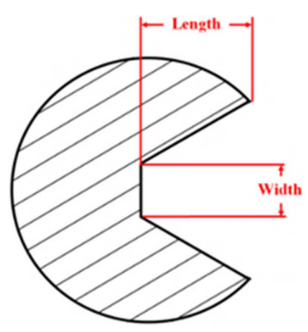

(b) Optimized geometry of fan-stub patch

Fig. 3 The geometry of fan-stub patch

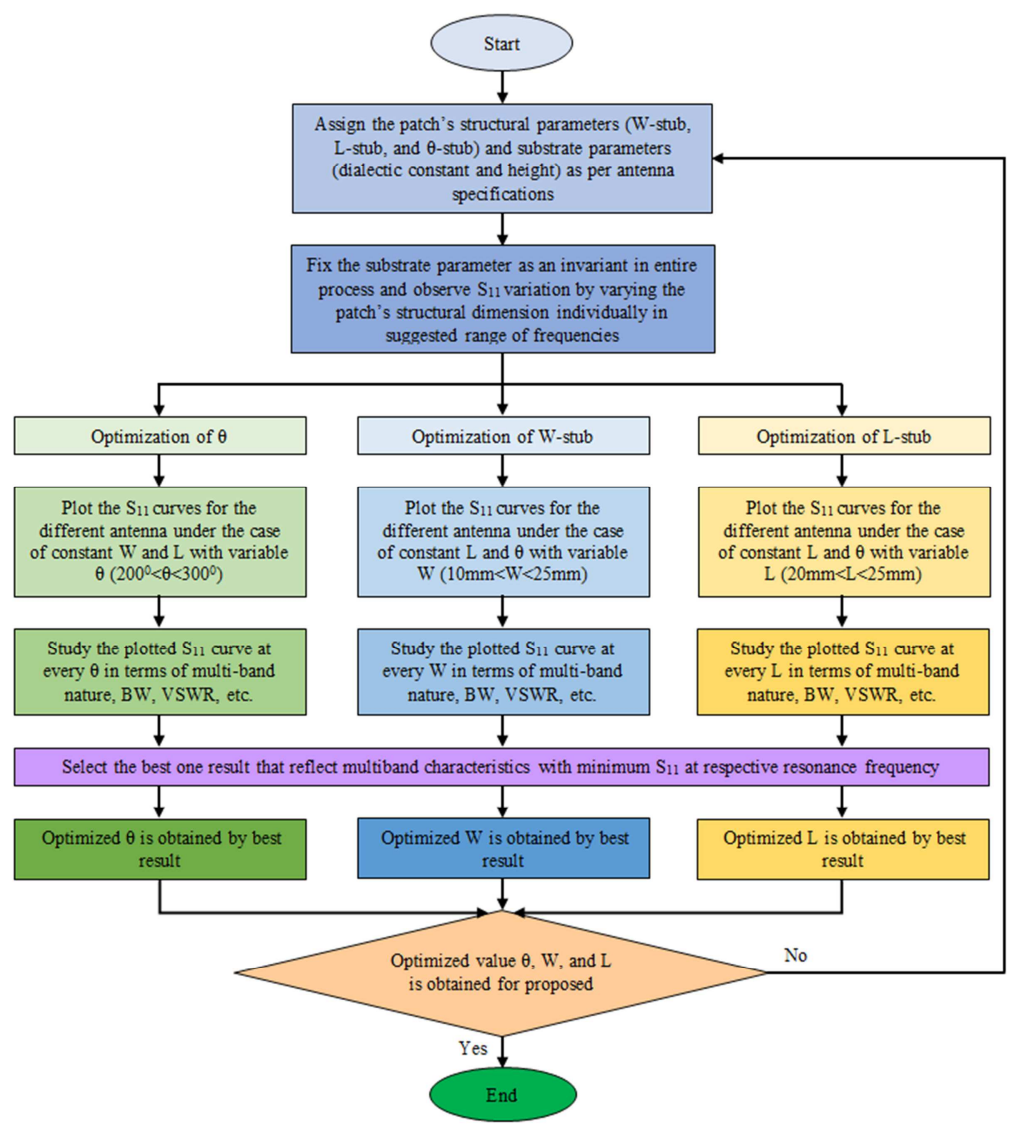

Fig. 4 The optimization flow chart for proposed antenna 
This work is dedicated to LTE-43, LTE-48, and 5.5 GHz WLAN bands applications, therefore its concerned frequency range from $3 \mathrm{GHz}$ to $6 \mathrm{GHz}$ is taken as a frequency of interest for investigation. To optimize the antenna performance within the range of frequencies $(3 \mathrm{GHz}$ to $6 \mathrm{GHz}$ ) and to create multiband features in the antenna, the optimization of antenna dimensions (at constant substrate height and $\varepsilon_{r}$ ) is worked out as shown in Fig. 4. To ensure the maximum wave power transfer from the cable to the respective antenna, the adjustment of the return loss $\mathrm{S}_{11}$ within the bandwidth (BW) is also justified.

\subsection{The optimization of stub angle $\theta$ for lowest return loss $S_{11}$}

In this section, the influence of stub angle $\theta$ variation on $\mathrm{S}_{11}$ at constant value of the stub width $W$ and stub length $L$ is analyzed by a simulated graph. Sonnet Lite (V.15.53) is used to simulate the parametric variation response within a specified range of frequencies. Subsequently, it will help achieve the optimized value of the stub angle to get the satisfactory result. The assumed value of patch stub dimension is recorded in Table 1 and is used to plot the return loss $S_{11}$. The right column in Table 1 highlights the individual $S_{11}$ plot color for each patch as shown in Fig. 5. Here, the $S_{11}$ graph shows that the fan-stub shaped patch with larger stub angle causes more declination in the return loss at the higher frequency found outside the resonance band. However, at constant patch width and length, the stub angle of $220^{\circ}$ shows the steep fall in return loss (minimum return loss window) around $5.8 \mathrm{GHz}$, which ensures and predicts the existence of multiband at this angle for another stub width and length. Therefore, the stub angle of $220^{\circ}$ is suitable for our objective.

Table 1 Fan-stub patch with variable angle

\begin{tabular}{|c|c|c|c|}
\hline Stub width $(\mathrm{mm})$ & Stub length $(\mathrm{mm})$ & Stub angle (degree) & $\mathrm{S}_{11}$ graph color in Fig. 5 \\
\hline 5 & 10 & 300 & Pink \\
\hline 5 & 10 & 260 & Red \\
\hline 5 & 10 & 220 & Blue \\
\hline
\end{tabular}

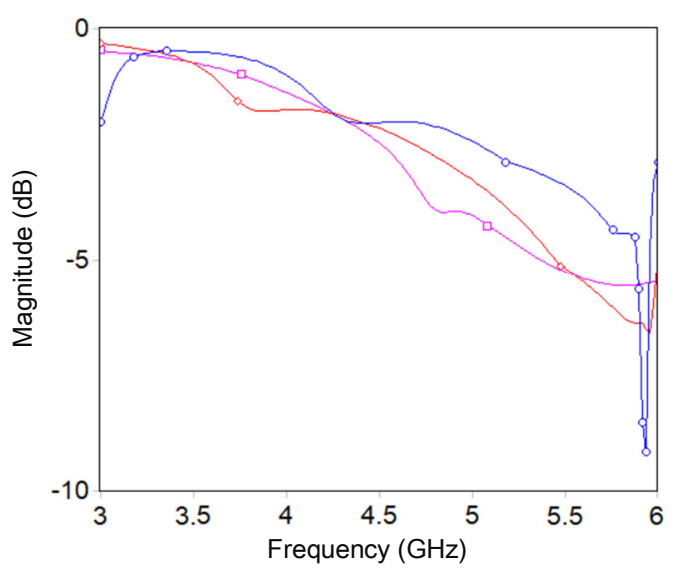

Fig. 5 The influence of stub angle $\theta$ variation on $\mathrm{S}_{11}$

\subsection{The optimization of stub width $W$ for lowest return loss $S_{11}$}

Fig. 6 reveals the simulated return loss $S_{11}$ graph for different widths of fan-stub structure, ranging from $10 \mathrm{~mm}$ to $20 \mathrm{~mm}$ at constant value of length and angle as tabulated in Table 2 . The right column in Table 2 reflects the color identification among the $S_{11}$ plots for the specified patch stub illustrated in Fig. 6.

Fig. 6 shows that the generation of the frequency band is strongly affected by the width $W$ variation, in which the lower value of width $W$ creates the first band at a higher range of frequency (having resonance frequency of $4.78 \mathrm{GHz}$, at $W=10 \mathrm{~mm}$ ), and the larger value of width $W$ yields the first band at a lower range of frequency (having resonance frequency of $4.08 \mathrm{GHz}$, at $W=20 \mathrm{~mm}$ ) with small variation of return loss. However, the larger patch width $W$ is the cause of larger flaring in a patch structure and also the cause of multiband generation. Hence, finally, a better response can be observed at $W=25 \mathrm{~mm}$. 
Table 2 Fan-stub patch with variable width $W$

\begin{tabular}{|c|c|c|c|}
\hline Stub width $(\mathrm{mm})$ & Stub length $(\mathrm{mm})$ & Stub angle (degree) & $\mathrm{S}_{11}$ graph color in Fig. 6 \\
\hline 15 & 25 & 220 & Blue \\
\hline 20 & 25 & 220 & Pink \\
\hline 25 & 25 & 220 & Red \\
\hline
\end{tabular}

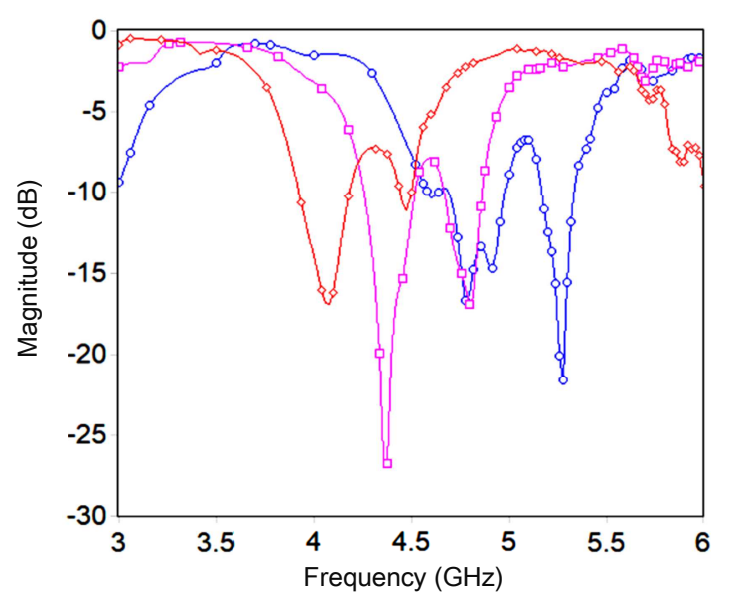

Fig. 6 The influence of stub width $W$ variation on $S_{11}$

\subsection{The optimization of stub length L for lowest return loss $S_{11}$}

Table 3 shows that the change in length for a fan-stub antenna at constant width $W$ and angle $\theta$ affects the return loss $S_{11}$. A specific color (the rightmost column in Table 3) is assigned to distinguish the $S_{11}$ plot for each patch. The simulated return loss $S_{11}$ graph for the suggested patch with the variable length $L$, ranging from $15 \mathrm{~mm}$ to $25 \mathrm{~mm}$, is reported in Fig. 7 . Here, it can be significantly noticed that the variation of antenna length $L$ results in major changes in return loss in the primary frequency band. The larger antenna length $L$ in fan-stub patch generates the wider primary band (for example, the primary band having BW of $400 \mathrm{MHz}$ is created at $L=25 \mathrm{~mm})$ with smaller value of $\mathrm{S}_{11}(-33.59 \mathrm{~dB})$ including multi band characteristics. The smaller antenna length $L$ inserts a primary band at a lower range of frequency with higher value of $\mathrm{S}_{11}(-18.1 \mathrm{~dB}$ at $L=15$ $\mathrm{mm}$ ). Since the return loss of $-33.59 \mathrm{~dB}$ is found at the antenna length of $25 \mathrm{~mm}$ among all values of $L$, the optimized value of stub length is locked at $25 \mathrm{~mm}$ to achieve the objective and applications of the proposed antenna.

Table 3 Fan-stub patch with variable length $L$

\begin{tabular}{|c|c|c|c|}
\hline Stub width $(\mathrm{mm})$ & Stub length $(\mathrm{mm})$ & Stub angle (degree) & $\mathrm{S}_{11}$ graph color in Fig. 7 \\
\hline 15 & 15 & 220 & Blue \\
\hline 15 & 20 & 220 & Red \\
\hline 15 & 25 & 220 & Pink \\
\hline
\end{tabular}

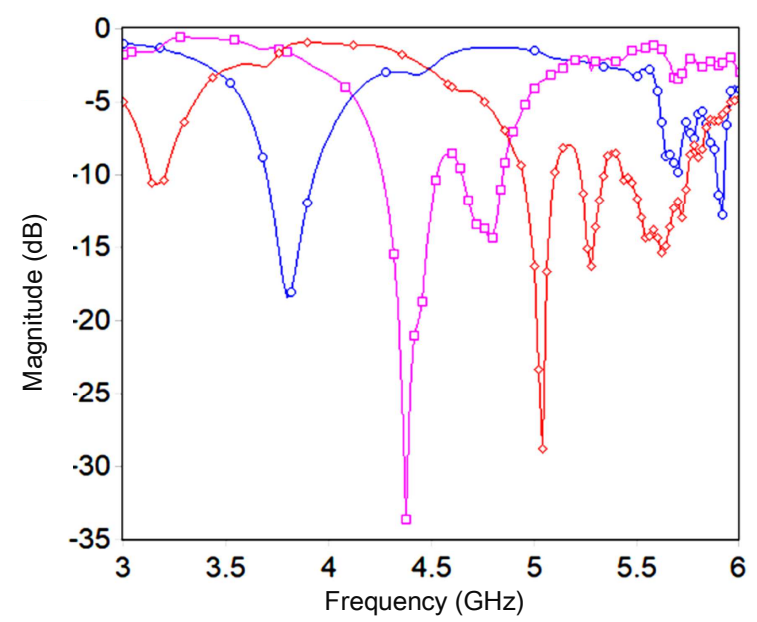

Fig. 7 The influence of stub length $L$ variation on $\mathrm{S}_{11}$ 
It is worth noting that we do not consider any substrates other than Rogers RT3035 $\left(\varepsilon_{r}=3.6\right.$, loss tangent $\left.=0.0018\right)$ because the comparative analysis as shown in Fig. 8 indicates that the thicker substrates with low dielectric constant value such as Rogers RT5880 ( $\varepsilon_{r}=2.2$, loss tangent $\left.=0.0009\right)$, Rogers RT5870 $\left(\varepsilon_{11}=2.33\right.$, loss tangent $\left.=0.002\right)$, Arlon AD450 $\left(\varepsilon_{r}=4.5\right.$, loss tangent $\left.=0.0035\right)$, etc. do not achieve the resonance at optimized value of $W, L$, and $\theta$ for CBRS and WLAN bands in fan-stub structure. Furthermore, the obtained multi-bands by Rogers RT5880, Rogers RT5870, and Arlon AD450 have low BW along with higher return loss $\left(\mathrm{S}_{11}>-18 \mathrm{~dB}\right)$. Therefore, in an antenna design, it could possibly not be accepted in active terrestrial mobile communication with proper transmitting power limit irrespective of desired bands.

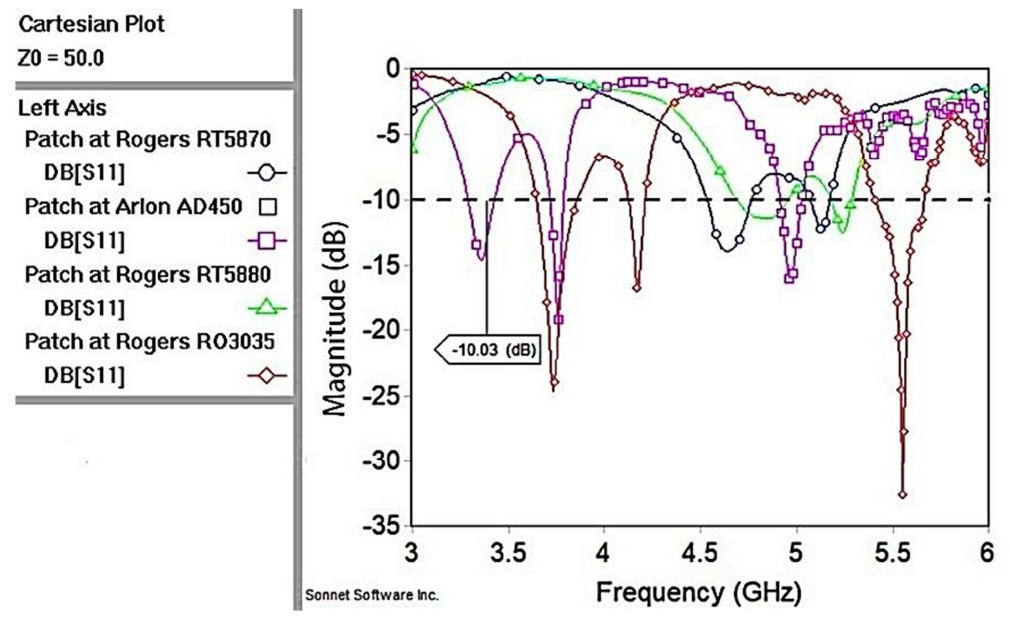

Fig. 8 The influence of different substrate material on $S_{11}$ for a fan-stub patch $\left(W=25 \mathrm{~mm}, L=25 \mathrm{~mm}\right.$, and $\left.\theta=220^{\circ}\right)$

\section{Designing Specifications and Simulation Results}

\subsection{Designing specification for proposed antenna}

In order to make the antenna as suitable as possible for optimum performance, the center feed antenna is fabricated on 4.6 mm thicker Rogers (RO3035) substrate with the proposed structure. The dimensional value of fan-stub shaped antenna is decided and derived from its optimized response. Final 2D and 3D geometry of the optimized antenna with its dimension is shown in Fig. 9(a) and in Fig. 9(b) respectively. The antenna structure is very simple and easy in manufacturing. The best result is expected to be found at $W=25 \mathrm{~mm}, L=25 \mathrm{~mm}$, and $\theta=220^{\circ}$.

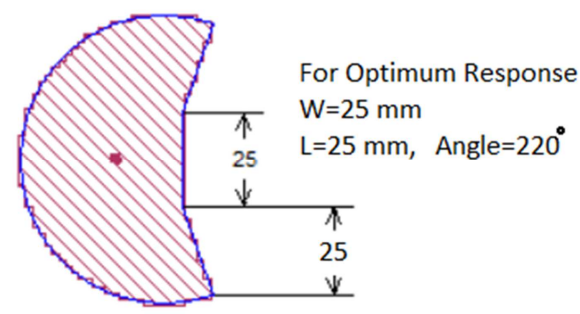

(a) 2D view of optimized fan-stub patch

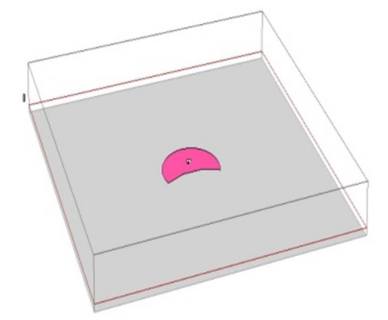

(b) 3D view of optimized fan-stub patch

Fig. 9 The schematic view of proposed fan-stub patch

\subsection{Simulation results}

The designed antenna performance is explored on the basis of its return loss $S_{11}$ for each band, including other deciding factors such as VSWR, input impedance $Z_{i}$, surface current distribution at different frequencies, etc. Fig. 10 presents the performance of the antenna in its multi-band behavior with the respective value of $S_{11}$ at its corresponding resonance frequency. The simulated return loss plot ensures the existence of triband characteristics, and it is found from $3.65 \mathrm{GHz}$ to $3.86 \mathrm{GHz}$ (5.61\% BW), $4.13 \mathrm{GHz}$ to $4.21 \mathrm{GHz}(1.91 \% \mathrm{BW})$, and $5.41 \mathrm{GHz}$ to $5.67 \mathrm{GHz}(4.68 \% \mathrm{BW})$. The first frequency band $(3.65 \mathrm{GHz}$ 
to $3.86 \mathrm{GHz}$ ) is enough to cover the entire LTE-43 band and major portion of LTE-48 band with all radiation features. The second frequency band $(4.13 \mathrm{GHz}$ to $4.21 \mathrm{GHz})$ and the third frequency band $(5.41 \mathrm{GHz}$ to $5.67 \mathrm{GHz})$ may be additionally reserved for future band expansion for LTE and WLAN application respectively. Fig. 11 illustrates VSWR versus frequency graph of the designed and suggested antenna. VSWR in all bands are less than 2 and reaches closer to 1 at the central resonance frequency.

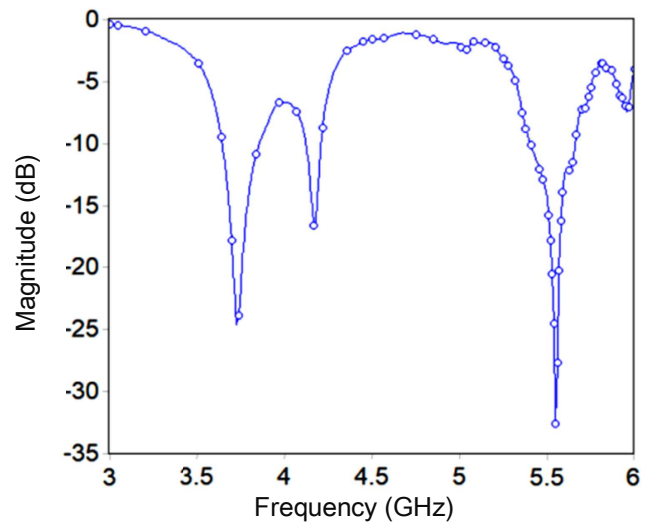

Fig. 10 The simulated $S_{11}$ plot of proposed and optimized patch

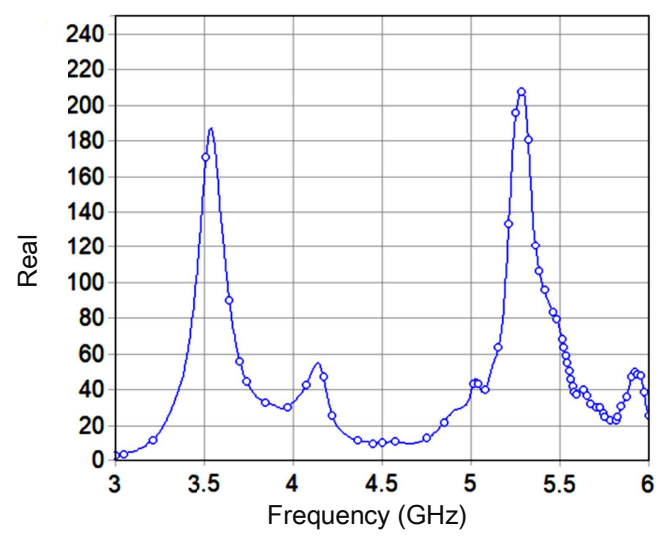

Fig. 12 The real part of input impedance with frequency variation

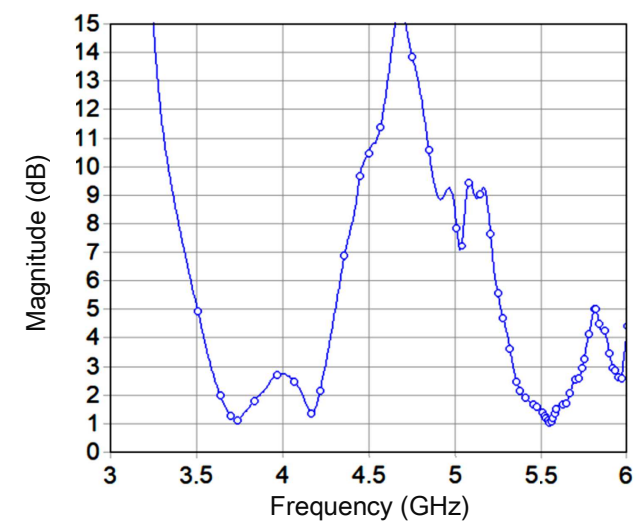

Fig. 11 The simulated VSWR plot of proposed and optimized patch

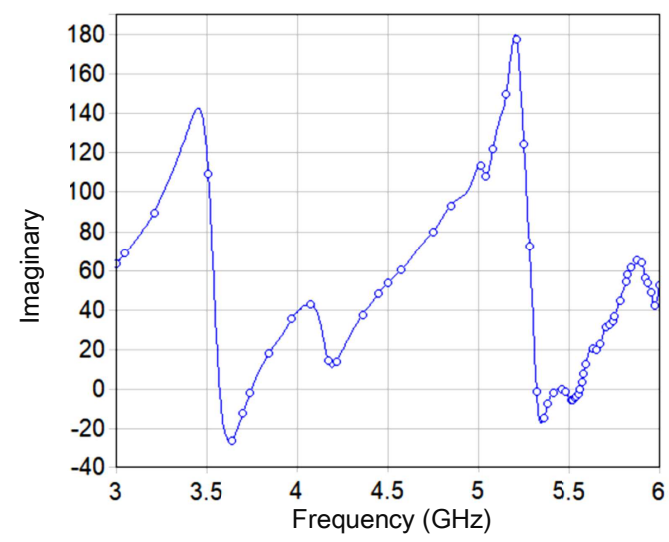

Fig. 13 The imaginary part of input impedance with frequency variation

The frequency dependence on input impedance $\mathrm{Z}_{\mathrm{i}}$ in terms of its real and imaginary part is depicted in Fig. 12 and in Fig. 13 respectively. The phase variation of the input impedance is demonstrated in Fig. 14 and exclusively proves its linearity over the entire operating band. Additionally, a two dimensional (in xy-plane) version of current density $J$ followed by Ohms Law is also computed graphically. The current density (JXY) is proportional to the tangential electric field strength over the area of patch surface. Therefore, this current density has to be used to see how an antenna radiates electromagnetic (EM) waves as a beam. The surface current distribution plots over the patch at central resonance frequency of $3.74 \mathrm{GHz}$ (first band), $4.17 \mathrm{GHz}$ (second band), and $5.55 \mathrm{GHz}$ (third band) depicted in Fig. 15. The figures sufficiently illustrate strong stability and acuteness of the concentration of surface current distribution within the band frequencies. Also, they depend upon central resonance frequencies. However, a variation in JXY can be further seen at constant resonance frequency if a different phase angle is found with respective frequency. For example, the JXY plot at the resonance frequency of $5.55 \mathrm{GHz}$ with different phase angles such as $30^{\circ}, 60^{\circ}, 90^{\circ}, 120^{\circ}$, and $150^{\circ}$ can be seen in Fig. 16. Hence, the observed JXY reveals that the strong EM fields are presented across peripheries of the patch stub width $W$ pointing toward patch center and are non-negligible.

VSWR circle (2.0) is added to Smith plot and is shown in Fig. 17 with red color, which confines and shows all those frequencies which come under VSWR $\leq 2$. 


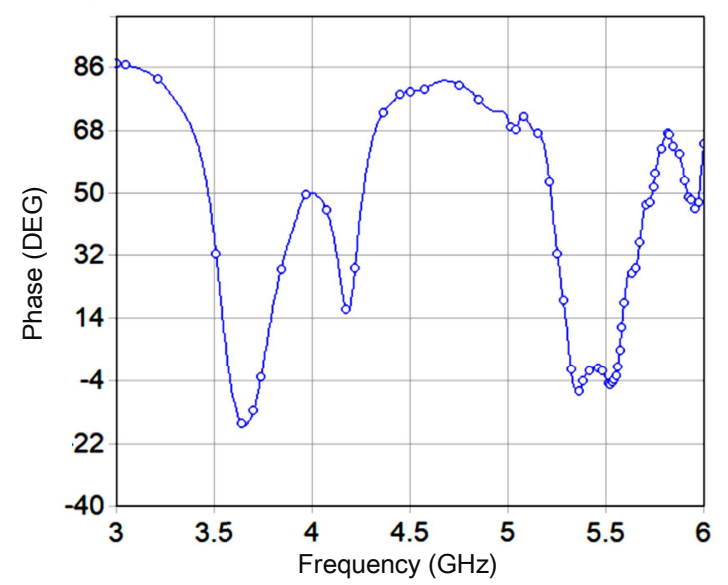

Fig. 14 The phase variation of input impedance with frequency variation

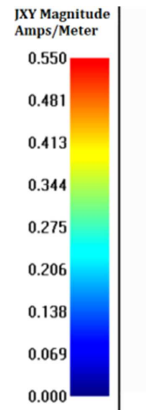

(a) The surface current distribution at $3.74 \mathrm{GHz}$

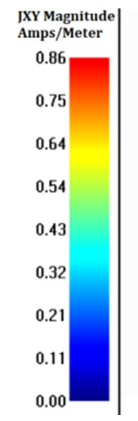

(b) The surface current distribution at $4.17 \mathrm{GHz}$
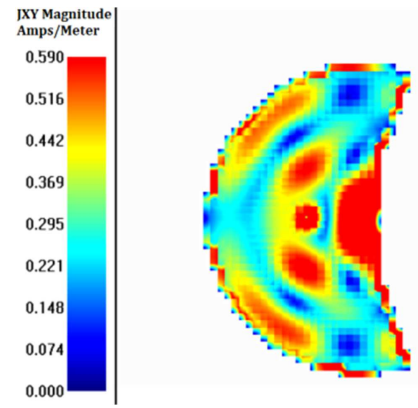

(c) The surface current distribution at $5.55 \mathrm{GHz}$

Fig. 15 The surface current distribution at central resonance frequencies (at phase angle of $0^{\circ}$ ) in tri-band

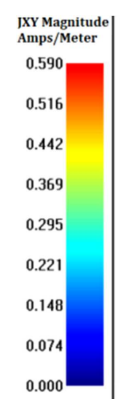

(a) The surface current distribution at $5.55 \mathrm{GHz}$ at $30^{\circ}$

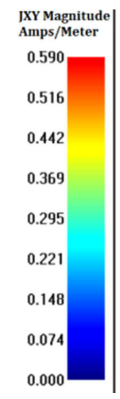

(c) The surface current distribution at $5.55 \mathrm{GHz}$ at $90^{\circ}$

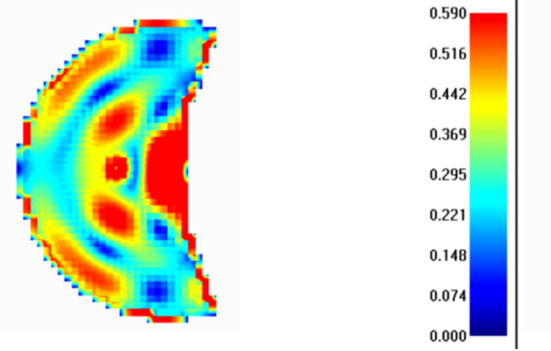

(d) The surface current distribution at $5.55 \mathrm{GHz}$ at $120^{\circ}$
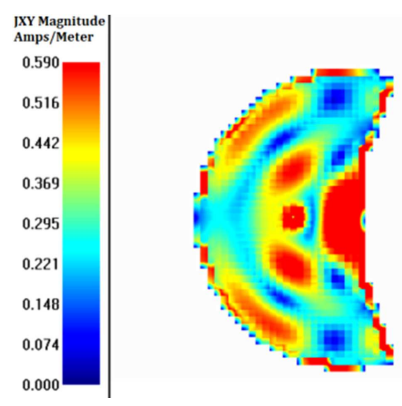

(b) The surface current distribution at $5.55 \mathrm{GHz}$ at $60^{\circ}$

Fig. 16 The surface current distribution at $5.55 \mathrm{GHz}$ at difference phase angle

The VSWR value for a given circle may be determined directly from the chart coordinate system. It can be defined by reading the resistance value. Here the VSWR circle crosses the resistance axis to the right of prime center (where the circle crosses the resistance axis to the left of prime center indicates the inverse ratio) [33]. 


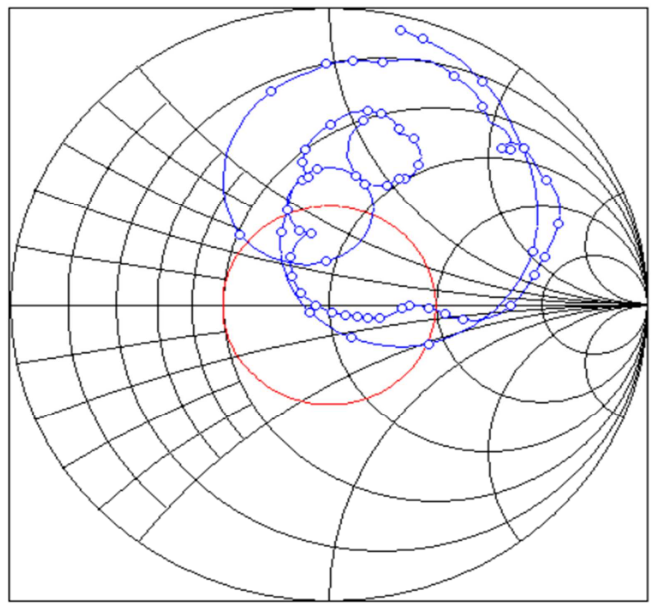

Fig. 17 The Smith plot impedance with VSWR (2.0) circle at characteristics impedance $\mathrm{Z}_{0}$ of $50 \mathrm{ohm}$

\section{Results and Discussion}

The consequences of the optimized and designed antenna reveal that apart from the substrate $\left(\varepsilon_{r}\right)$ and its height, the feeding technique, impedance matching, stub width, stub length, and stub angle (in the case of angular patch) are strongly linked to the effect of optimization. The width $W$ and length $L$ of the patch stub are taken as control variables at the constant stub angle of $220^{\circ}$. The proposed antenna begins its first frequency band from $3.65 \mathrm{GHz}$ to $3.86 \mathrm{GHz}$ with VSWR $\leq 2$, and is suitable to cover LTE-48 and LTE-49 bands. The achieved $S_{11}$ and VSWR at central resonance frequency in this first window are $-23.9 \mathrm{~dB}$ and 1.13 respectively. The second frequency band has a narrow $\mathrm{BW}$ of $80 \mathrm{MHz}$, and its central resonance frequency $(4.17 \mathrm{GHz})$ shows higher value of $\mathrm{S}_{11}$ and VSWR in contrast to the first frequency band, that is $-16.63 \mathrm{~dB}$ and 1.35 respectively. The third frequency band has the range from $5.41 \mathrm{GHz}$ to $5.67 \mathrm{GHz}$ with $\mathrm{BW}$ of $260 \mathrm{MHz}$, and its VSWR value lies in between 1.04 to 2. The generated third band is suitable for 5.5 GHz WLAN applications. Rapid changes in the real and imaginary part of the input impedance $\mathrm{Z}_{\mathrm{i}}$ result in the narrow operating frequency band. The concentration of surface current distribution over the patch antenna is very stable at its operating band of frequency and does not change with the change of phase angle.

\section{Conclusions}

In this study, a single layer fan-stub shaped triband antenna is presented. The simulated result concludes that the stub length $L$ and stub width $W$ of the designed antenna is the chief performance controlling dimension. The fan-stub antenna with larger width $W$ generates working feasibility at lower frequency band. This antenna also provides the extra BW support of 160 $\mathrm{MHz}$ to the upper end of the existing LTE-48 band from $3650 \mathrm{MHz}$ to $3860 \mathrm{MHz}$ with $\mathrm{S}_{11}<-10 \mathrm{~dB}$. The resultant primary band fully covers the LTE-43 band, and the additional BW of $10 \mathrm{MHz}$ and $160 \mathrm{MHz}$ are found at its lower and upper ends of spectrum. Consequently, the extended BW is perfectly matched and enough for the telecommunications services that support ultra-high resources, and it could be versatile to $4.9 \mathrm{G}$ and $5 \mathrm{G}$ technology based network deployment. Furthermore, the enhanced BW may be utilized to restrict channel congestion in several applications, such as in wireless sensor networks, in remote control and sensing, in security remote controlled cameras, in industrial and agriculture equipment, etc. In future, this work may be expanded to cover the LTE-42 band, LTE-49 band, and WLAN $5.5 \mathrm{GHz}$ band in the case of spectrum congestion. Spurious band-notched characteristics of the proposed antenna can be eliminated and filtered out by adjusting the length $L$, width $W$, orientation, and feeding point of the slotted patch.

\section{Conflicts of Interest}

The authors declare no conflict of interest. 


\section{Acknowledgments}

The authors should like express their gratitude to lecturer Mrs. Yusupova Mahri for her help in writing this paper.

\section{References}

[1] A. K. Rastogi, G. Pravin, and S. Sharma, "Comparative Study of Rectangular and E-Shaped Microstrip Patch Antenna Array for X-Band Applications,” Advanced Computing and Communication Technologies, pp. 195-203, July 2019.

[2] X. Yang, J. Xiao, J. Wang, and L. Sheng, "Compact Frequency Reconfigurable Antennas Based on Composite Right/Left-Handed Transmission Line,” IEEE Access, vol. 7, pp. 131663-131671, September 2019.

[3] A. H. Nazeri, A. Falahati, and R. M. Edwards, "A Novel Compact Fractal UWB Antenna with Triple Reconfigurable Notch Reject Bands Applications,” International Journal of Electronics and Communications, vol. 101, pp. 1-8, January 2019.

[4] G. Yang, S. Zhang, J. Li, Y. Zhang, and G. F. Pedersen, “A Multi-Band Magneto-Electric Dipole Antenna with Wide Beam-Width,” IEEE Access, vol. 8, pp. 68820-68827, April 2020.

[5] M. Dvorsky, H. S. Ganesh, and S. S. Prabhu, "Design and Validation of an Antipodal Vivaldi Antenna with Additional Slots," International Journal of Antennas and Propagation, vol. 2019, pp. 1-10, May 2019.

[6] S. Kamal, A. S. B. Mohammed, M. F. B. Ain, F. Najmi, R. Hussin, Z. A. Ahmad, et al., "A Novel Lumped LC Resonator Antenna with Air-Substrate for 5G Mobile Terminals," Progress in Electromagnetics Research Letters, vol. 88, pp.75-81, 2020.

[7] I. Parvez, M. G. S. Sriyananda, E. Güvenç, M. Bennis, and A. Sarwat, "CBRS Spectrum Sharing between LTE-U and WiFi: A Multiarmed Bandit Approach,” Mobile Information Systems, vol. 2016, pp.1-12, July 2016.

[8] R. Zhang, M. Wang, L. X. Cai, Z. Zheng, X. S. Shen, and L. L. Xie, "LTE-Unlicensed: The Future of Spectrum Aggregation for Cellular Networks," IEEE Wireless Communications, vol. 22, no. 3, pp. 150-159, June 2015.

[9] D. M. In, M. J. Lee, D. Kim, C. Y. Oh, and Y. S. Kim, “Antipodal Linearly Tapered Slot Antenna Using Unequal Half-Circular Defected Sides for Gain Improvements," Microwave and Optical Technology Letters, vol. 54, no. 8, pp. 1963-1965, May 2012.

[10] J. Zhang, S. Liu, F. Wang, Z. Yang, and X. Shi, “A Compact High-Gain Vivaldi Antenna with Improved Radiation Characteristics," Progress In Electromagnetics Research Letters, vol. 68, pp.127-133, June 2017.

[11] D. M. Elsheakh and E. A. Abdallah, "Ultrawideband Vivaldi Antenna for DVB-T, WLAN, and WiMAX Applications," Hindawi Publishing Corporation, International Journal of Antennas and Propagation, vol. 2014, pp.1-7, Febraury 2014.

[12] D. S. Cabral, L. Manera, and L. B. Zoccal, "Design and Application of a Compact UWB Antipodal Vivaldi Antenna," IEEE 17th International Conference on Ubiquitous Wireless Broadband, pp. 1-5, September 2017.

[13] D. V. N. Mendez, L. F. C.Suarez, E. A. Daviu, M. F. Bataller, M. B. Escudero, E. Antonio, et al., "Compact Wideband Vivaldi Monopole for LTE Mobile Communications," IEEE Antennas and Wireless Propagation Letters, vol. 14, pp. 1068-1071, January 2015.

[14] J. Y. Siddiqui, Y. M. M. Antar, A. P. Freundorfer, E. C. Smith, G. A. Morin, and T. Tayaparan, "Design of an Ultrawideband Antipodal Tapered Slot Antenna Using Elliptical Strip Conductors," IEEE Antennas and Wireless Propagation Letters, vol. 10, pp. 251-254, March 2011.

[15] Z. Wang, Y. Yin, J. Wu, and R. Lian, “A Miniaturized CPW Fed Antipodal Vivaldi Antenna with Enhanced Radiation Performance for Wideband Applications,” IEEE Antennas and Wireless Propagation Letters, vol. 15, pp. 16-19, April 2015.

[16] J. D. S. Langley, P. S. Hall, and P. Newham, "Balanced Antipodal Vivaldi Antenna for Wide Bandwidth Phased Arrays," IEE Proceedings on Microwaves, Antennas and Propagation, vol. 143, no. 2, pp. 97-102, April 1996.

[17] M. Moosazadeh, A. M. Abbosh, and Z. Esmati, "Design of Compact Planar Ultrawideband Antenna with Dual-Notched Bands Using Slotted Square Patch and Pi-Shaped Conductor-Backed Plane," IET Microwaves, Antennas and Propagation, vol. 6, no. 3, pp. 290-294, April 2012.

[18] L. Wezranovski, Z. Urban, L. Ivanek, and Y. Zakaria, "Patch Antenna Optimization in COMSOL Multiphysics," ELEKTRO, May 2016, pp. 104-109.

[19] S. Baudha and M. V. Yadav, "A Novel Design of a Planar Antenna with Modified Patch and Defective Ground Plane for Ultra-Wideband Applications,” Microwave and Optical Technology Letters, vol. 61, no. 5, pp. 1320-1327, January 2019. 
[20] M. V. Yadav and S. Baudha, "A Miniaturized Printed Antenna with Extended Circular Patch and Partial Ground Plane for UWB Applications,” Wireless Personal Communications, vol. 116, pp. 311-323, January 2021.

[21] R. S. Uqaili, J. A. Uqaili, S. Zahra, F. B. Soomro, and A. Akbar, "A Study on Dual-Band Microstrip Rectangular Patch Antenna for Wi-Fi," Proceedings of Engineering and Technology Innovation, vol. 16, pp. 1-12, August 2020.

[22] J. Yang and A. Kishk, "A Novel Low-Profile Compact Directional Ultra-Wideband Antenna: The Self-Grounded Bow-Tie Antenna," IEEE Transactions on Antennas and Propagation, vol. 60, no. 3, pp. 1214-1220, March 2012.

[23] S. I. Latif, D. F. Tapia, S. Pistorius, and L. Shafai, "Design and Performance Analysis of the Miniaturised Water-Filled Double-Ridged Horn Antenna for Active Microwave Imaging Applications," IET Microwaves, Antennas \& Propagation, vol. 9, no. 11, pp. 1173-1178, 2015.

[24] S. I. Latif, D. F. Tapia, D. R. Herrera, M. S. Nepote, S. Pistorius, and L. Shafai, “A Directional Antenna in a Matching Liquid for Microwave Radar Imaging,” International Journal of Antennas and Propagation, vol. 2015, pp. 1-8, November 2015.

[25] Y. H. Qian and Q. X. Chu, “A Broadband Hybrid Monopole-dielectric Resonator Water Antenna,” IEEE Antennas and Wireless Propagation Letters, vol. 16, pp. 360-363, 2017.

[26] M. Wang and Q. X. Chu, "High-Efficiency and Wideband Coaxial Dual-Tube Hybrid Monopole Water Antenna," IEEE Antennas and Wireless Propagation Letters, vol. 17, no. 5, pp. 799-802, May 2018.

[27] S. Rashid, L. Jofre, A. Garrido, G. Gonzalez, Y. Ding, A. Aguasca, et al., "3D Printed UWB Microwave Bodyscope for Biomedical Measurements," IEEE Antennas and Wireless Propagation Letters, vol. 18, no. 4, pp. 626-630, April 2019.

[28] A. K. Singh Pundir, A. Yadav, and S. Das, Recent Trends in Communication and Intelligent Systems, Singapore: Springer Singapore, 2021.

[29] Y. Dong, H. Toyao, and T. Itoh, "Design and Characterization of Miniaturized Patch Antennas Loaded with Complementary Split-Ring Resonators," IEEE Transactions on Antennas and Propagation, vol. 60, no. 2, pp. 772-785, Febraury 2012.

[30] K. A. Khan, S. Singh, and A. Jha, "Single-Layer Single Patch Quad Band Antenna for S\&C Band Application," International Journal of Innovative Science, Engineering \& Technology, vol. 2, no. 7, pp. 372-375, July 2015.

[31] K. A. Khan, A. Jha, and D. V. Gupta, "Design, Simulation and Analysis of Penta Band Micro-Strip Patch Antenna for UNII \&C Band Application,” International Journal of Innovative Science, Engineering \& Technology, vol. 2, no. 8, pp. 9-12, August 2015.

[32] W. C. Mok, S. H. Wong, K. M. Luk, and K. F. Lee, "Single-Layer Single-Patch Dual-Band and Triple-Band Patch Antennas," IEEE Transactions on Antennas and Propagation, vol. 61, no. 8, pp. 4341-4344, August 2013.

[33] C. MacKeand, “The Smith Chart in BASIC," QST, pp. 28-31, November 1984. 